\title{
O BRASIL NA ATUAL ORDEM MUNDIAL
}

\author{
Amado Luiz Cervo ${ }^{1}$
}

\section{Introdução}

O modelo brasileiro de inserção internacional aprofunda, no século XXI, a aliança entre Estado e sociedade e eleva o grau de maturidade. Ação diplomática, política exterior e movimento de atores não governamentais que perseguem interesses específicos por meio de suas iniciativas externas compõem o tripé de nosso conceito de inserção internacional. Convém, pois, aprofundar os três componentes da inserção internacional, que não se reduz mais como se imaginava no passado à conduta da diplomacia ou à política exterior, mesmo que esta agregue àquela as percepções do interesse nacional.

Qual terá sido a mudança quanto à funcionalidade do Estado? Depois de ser Estado desenvolvimentista e centralizador, depois do Estado neoliberal que entregava as forças da economia e da sociedade a seu próprio curso sem apoiá-las, terá o Estado assimilado o fenômeno mais marcante das duas últimas décadas, ou seja, a emergência da sociedade, que se manifesta por meio de atores e poderes? Como conceituar essa nova funcionalidade?

Os instrumentos de poder acionados pelos três componentes da inserção internacional no século XXI constituem outro desafio intelectual à compreensão do tema. Qual o papel da integração, das coalizões emergentes e das velhas e novas parcerias, não apenas como instrumentos de poder, mas ainda como vias efetivas de realização de interesses?

A diplomacia se movimenta no século XXI à base do princípio da reciprocidade de benefícios. Nos domínios das negociações comerciais e de

\footnotetext{
1 Professor Titular de História das Relações Internacionais da Universidade de Brasília. Emérito. Pesquisador Sênior do Conselho Nacional de Desenvolvimento Científico e Tecnológico-CNPq (alcervo@unb.br).
} 
segurança internacional, das questões ambientais e dos direitos humanos, o princípio da reciprocidade pretende penetrar a velha ordem, cujas regras ou ordenamentos eram determinados pela prevalência decisória das nações avançadas em seu próprio proveito. A velha ordem teceu e prolongou o mundo das assimetrias. $O$ princípio da reciprocidade de benefícios postula, nesse sentido, condições para promover mais igualdade entre as nações.

Entende-se, pois, por que três objetivos de poder sejam visualizados pelo BRICS, o grupo que representa os interesses do mundo em desenvolvimento: estabelecer nova estratégia internacional de segurança, promover regras de comércio e finanças que se voltem para a superação da desigualdade entre as nações e, enfim, a requisição de maior poder nas instâncias financeiras globais no intuito de tornar efetivas ambas as estratégias.

Nada mais surpreendente para a inserção internacional do Brasil no século XXI do que o processo de internacionalização de sua economia. Como se desencadeia, que direções geográficas toma, que benefícios traz? Observa-se, com efeito, que a expansão global dos empreendimentos brasileiros ocorre em ritmo acelerado no século XXI e que estabelece um nível de interdependência que permite ao historiador perguntar: o país, enfim, atinge sua maturidade no sistema de economia de mercado que norteia as relações econômicas internacionais?

O quadro da análise da inserção internacional do Brasil no século XXI não seria objetivo sem desvendar os limites da ação diplomática e da política exterior, que por certo condicionam o movimento dos agentes econômicos, os mais relevantes para o bem estar da sociedade. Por isso, além de conceituar o Estado logístico, insistimos em identificar seus ainda graves limites de eficiência.

Esse esquema, determinado por questões chaves e conectadas, à base do referencial conceitual que elaboramos nas últimas décadas acerca das relações internacionais do Brasil, nos permite construir o argumento cognitivo e explicativo, bem como promover a avaliação de resultados acerca do atual modelo brasileiro de inserção internacional. 


\section{Amado Luiz Cervo}

\section{1 - O Estado Logístico: a nova funcionalidade do Estado}

Os dirigentes do século XXI tomam consciência do papel do Estado, ao requisitar a ação política com o fim de fazer a nação penetrar os processos globais como agente do sistema.

A mudança do paradigma do Estado, isto é, a mudança da funcionalidade, ocorre no Brasil em tempo de média duração e por duas razões.

O velho Estado desenvolvimentista responsável pelo grau de desenvolvimento alcançado de 1930 a 1980, especialmente por agregar continuidade e racionalidade ao processo de industrialização do país, alcança os anos 1980 exibindo vícios graves, devidos à exacerbada introspecção: alto grau de protecionismo do mercado de consumo, com baixa produtividade dos sistemas produtivo industrial e de serviços, instabilidade monetária, endividamento externo e estagnação econômica. A exaustão do desenvolvimentismo era perceptível.

A ruptura que ocorre com o advento dos regimes neoliberais dos anos 1990 no Brasil e em toda a América Latina decorre dessa crise do modelo anterior. Caracterizado pela demolição do núcleo central robusto das economias nacionais, pela abertura incondicional do mercado e dos sistemas produtivo e de serviços, pelas privatizações das empresas públicas com alienação de seus ativos em favor de empresas estrangeiras, o neoliberalismo deteriorou, ademais, de acordo com dados da Cepal, as condições de renda, trabalho, saúde e bem estar das populações. O Brasil foi o único país da América Latina a exibir sérias hesitações diante dos resultados das reformas neoliberais. Fernando Henrique Cardoso que conduzia essa crítica elaborou o conceito de globalização assimétrica para significar sua relutância, e encaminhou o novo paradigma logístico, consolidado pelos dirigentes do século XXI.

Logístico é aquele Estado que não se reduz a prestar serviço, como fazia à época do desenvolvimentismo, nem a assistir passivamente às forças do mercado e do poder hegemônico, como se portava à época do neoliberalismo. Logístico porque recupera o planejamento estratégico do desenvolvimento e exerce a função de apoio e legitimação das iniciativas de outros atores econômicos e sociais, aos quais repassa responsabilidades e poder.

As relações entre Brasil e Estados Unidos exemplificam o modo como a conduta logística do Estado penetra as políticas exteriores: criar facilidades, 
induzindo oportunidades para que agentes econômicos e sociais operem com desenvoltura para realização de interesses específicos. Dois encontros recentes entre os chefes de Estado de Brasil e Estados Unidos evidenciam a maturidade do Estado logístico.

Em março de 2011, a presidente do Brasil, Dilma Rousseff, recebeu em Brasília o presidente dos EUA, Barack Obama, em sua primeira viagem ao país. Os dois dirigentes induziram oportunidades de negócios, firmando acordos no sentido de facilitar o movimento de comerciantes e investidores. Para tanto, criou-se na ocasião uma Comissão Brasil - Estados Unidos para Relações Econômicas e Comerciais com o fim de promover a cooperação na área energética, especialmente petróleo e etanol, visto estar o Brasil necessitando de investimentos e os Estados Unidos interessados no pré-sal brasileiro e na produção do biocombustível. A Comissão também cuidaria dos obstáculos ao comércio, como as sobretaxas, e de projetos na área de infraestrutura, cooperação espacial, educação, entre outras.

Durante a visita de Rousseff aos Estados Unidos em abril de 2012, o observador percebe como, por trás das preocupações dos dirigentes, são as sociedades que andam por si, após a emergência da sociedade brasileira desde os anos 1990. As negociações partem da suposição segundo a qual aos Estados cabe apoiar relações consistentes entre seus segmentos dinâmicos. Desse modo, admite-se de ambos os lados a autonomia das políticas exteriores, não se discute discordâncias acerca das intervenções da OTAN, dos direitos humanos e de Cuba, porém novos acordos são firmados, facilitando contatos e ações na área da educação, que incluem a cooperação científica e tecnológica e intercâmbio de professores e alunos de Universidades brasileiras com centros avançados como MIT e Harvard, cooperação entre Embraer e Boing na área empresarial, reconhecimento da cachaça (exportação cresce 100\% em 2012) e do Bourbon como bebidas genuínas do outro e promoção de seu comércio em atenção aos respectivos produtores, cooperação em segurança alimentar e desburocratização do fluxo bilateral de pessoas. As funções dos Estados acedem à condição de padrão de conduta convergente: eliminar obstáculos e promover oportunidades para a ação dos agentes das duas sociedades na busca de seus interesses setoriais. 


\section{Amado Luiz Cervo}

\section{2 - Emergência da sociedade: o insumo interno}

$O$ fator mais importante na origem do Estado Logístico é a emergência da sociedade. Ela permite à funcionalidade do Estado transitar de Estado todo poderoso, que arrastava atores ou agentes sociais com baixa margem de poder, autonomia e iniciativa, para outra condição, na qual o Estado transfere a tais atores ou agentes não governamentais poder e responsabilidade diante do desenvolvimento a promover. A modificação de uma a outra operacionalidade dos dois componentes, sociedade e Estado, passa pela crise neoliberal dos anos 1990, crise de fortalecimento da sociedade e de reordenamento do Estado.

Três causalidades colaboram para a consolidação do Estado logístico no Brasil do século XXI: a) a sociedade encontra-se em nível avançado de organização, com suas federações de classe articulando, setorialmente, industriais, agricultores, banqueiros, operários, comerciantes e consumidores, condição que facilita a função de coordenação superior do Estado guiado pelo interesse nacional, entendido como soma dos interesses setoriais; b) a estabilidade política e econômica, que sugere associar a lógica da governabilidade interna com a lógica da governança global à época da interdependência global; c) o nível comparativamente avançado dos agentes econômicos e sociais em termos de organização empresarial e competitividade sistêmica.

A emergência da sociedade no Brasil torna-se possível no rumo em que se processa no século XXI em razão de legado histórico, por um lado, e de mudança circunstancial por outro.

Desde os anos 1930, o governo de Getúlio Vargas incorporou à governabilidade, com característica de racionalidade a manter, o padrão de conduta segundo o qual os segmentos dinâmicos da sociedade - empresários industriais, agricultores, comerciantes, banqueiros, operários, consumidores e outros - não são excludentes nem conflitantes para os dirigentes e seus interesses sociais devem ser protegidos e promovidos com equilíbrio, porém todos eles, sem discriminação. O padrão de governabilidade irá descartar, desde então, políticas setoriais que castiguem um setor em benefício de outro, como ocorre, por exemplo, com o setor agrário e o urbano em outros países. Ao governo cabe incorporar o senso do interesse nacional, entendido como equalização de interesses por vezes conflitantes entre si, ou seja, harmonização 
dos interesses setoriais feita de promoção de todos eles e controle para evitar a imposição de um segmento em detrimento de outro. Assim, as políticas interna e externa tornam efetiva a noção de um superior interesse nacional, algo que, no Brasil, explica a harmonia entre Estado e sociedade, que se estabelece e se firma por sobre governos, partidos e regimes políticos.

$O$ elemento circunstancial que também explica o fortalecimento da sociedade no século XXI vem da experiência neoliberal da última década do século anterior, caracterizada pela hesitação, pela autocrítica e pela correção de rumos ainda quando em curso. Ou seja, dosagem do grau da abertura e das reformas ao grau de adaptabilidade das forças econômicas e da organização social. Essa dosagem permite associar o legado histórico referido anteriormente à contribuição de fatores positivos do neoliberalismo.

\section{3 - Instrumentalização da integração, coalizões de poder e parcerias: o insumo externo}

Certas condições sistêmicas da ordem internacional no século XXI favorecem a emergência do Brasil sobre o cenário internacional: reforço da interdependência econômica entre as nações, enfraquecimento do multilateralismo e dos processos de integração, fortalecimento do bilateralismo e do andar solto dos Estados nacionais, enfim, a crise nos Estados Unidos, Europa e Japão. Por outro lado, certas dificuldades decorrentes dessa crise, como a valorização cambial das moedas tradicionais, a desvalorização da moeda chinesa, a distorção da concorrência provocada por tais manipulações da moeda, os excedentes de produção industrial nos países centrais em razão da queda do consumo, entre outras, representam fatores que perturbam interesses e ascensão do Brasil.

Uma readaptação de estratégias externas é requisitada por tais circunstâncias. Examinamos a seguir alguns aspectos atinentes à integração, à formação de coalizões emergentes e a parcerias bilaterais.

A formação de blocos se mantém como tendência das relações internacionais no século XXI, sem, contudo, manifestar o dinamismo da década de 1990. Dois exemplos ilustram essa inflexão no processo de integração.

Em primeiro lugar, observa-se ritmo mais lento na União Europeia. $\mathrm{O}$ bloco desiste da Constituição, rejeitada por plebiscitos em 2005, e acaba por substituí-la pelo Tratado de Lisboa, que também não recolhe a unanimidade de 


\section{Amado Luiz Cervo}

seus 27 membros. Em segundo lugar, na América do Sul, se os governos alcançam resultados notáveis que melhoram as condições econômicas e sociais agravadas pelo neoliberalismo, a chamada inclusão social, fazem-no por meio de soluções introspectivas, centradas em projetos nacionais, que ignoram a integração. Esses governos programam, ademais, diferentes modelos de inserção internacional. Também aqui, alguns governos não entendem a integração como estratégia eficiente para superação de dificuldades próprias. Nessas condições, a política exterior brasileira, de forte caráter integracionista, passa por uma adaptação concreta: utiliza os processos de integração, antes tidos por uma espécie de fim em si, como meios para estabelecer ou consolidar a rede de cooperação e poder ao sul, partindo da América do Sul e avançando para alianças com outras regiões com o fim de realizar desígnio de país globalista.

Um dilema se põe à inserção internacional do Brasil: balancear seu projeto de integração e desenvolvimento regional, o mais consistente da América do Sul, com sua pretensão de potência emergente de alcance global, a mais viável na América do Sul. Esse dilema, é bem verdade, foi administrado com equilíbrio, tanto pelo presidente Fernando Henrique Cardoso, nos anos 1990, quanto por seu sucessor, Luiz Inácio Lula da Silva, na década seguinte. Ambos, e com respaldo das lideranças setoriais nacionais, empenharam-se fortemente em conduzir a nação nessas duas vias de ação externa, ao passo que Dilma Rousseff, que substitui Lula na Presidência em 2011, pende mais para a construção da potência global.

$O$ ponto de chegada desse dilema deixa perceber, enfim, que governo e sociedade estão mais propensos a atuar sobre o cenário global com a marca Brasil do que com as marcas Mercosul ou Unasul, enquanto anteriormente a hesitação prevalecia nesse terreno. Tal inflexão não equivale dizer, por certo, renúncia à integração regional, porém o reconhecimento de que a estratégia globalista adquire crescente relevância para o modelo brasileiro de inserção internacional. Ousaríamos avançar duas explicações para essa inflexão em favor do global: os problemas causados pelos países vizinhos, por um lado, e a percepção segundo a qual as instâncias globais contribuem de modo mais concreto e objetivo para a emergência do Brasil sobre o cenário internacional do que as instâncias regionais. 
A crise financeira e econômica desencadeada em 2007 nos países centrais serviu de motivo circunstancial para fortalecer a integração sul-americana. Em agosto de 2011, por ocasião da reunião dos 12 ministros das finanças da UNASUL em Buenos Aires, Guido Mantega, o ministro brasileiro, fez forte apelo à convergência dos membros do bloco em favor do crescimento regional. Propunha a criação de mecanismos sul-americanos de defesa econômica e de fomento ao comércio regional, bem como a ampliação do crédito, aproveitando a solidez fiscal dos países, como fórmulas de atenuar os efeitos negativos da crise.

A integração regional sul-americana, evolui, contudo, de prioridade alta para prioridade baixa na estratégia de ação internacional do Brasil, durante a primeira década do século XXI. Com efeito, desde o Mercosul e a UNASUL, a confecção de uma rede global se alça como propósito nacional. Dois poderosos instrumentos de ação são postos a serviço do propósito globalista. Por um lado, o multilateralismo da reciprocidade, movido pela diplomacia, destina-se ao exercício de pretensa liderança por meio de negociações globais que fortaleçam, ao menos permitam exibir, o poder nacional. Por outro lado, a internacionalização dos empreendimentos brasileiros, isto é, a expansão para fora de investimentos e negócios nacionais, estimulada por interesse pessoal de Lula, que aciona o Estado Logístico, e movida por reação favorável do meio empresarial, alcança todos os cantos do planeta. A rede global assenta-se, sob os dois aspectos, o político e o econômico, na América do Sul, onde lança raízes e se fortalece para depois estender-se ao mundo. A mudança de perspectiva, embora sutil, é clara: o lugar natural do Brasil não é mais a América do Sul, como a realidade anterior parecia sugerir, mas o mundo.

A institucionalização do BRICS ocorre em 2007, em grande medida por esforço do governo brasileiro, interessado em formar um bloco de países emergentes. Reunia então Brasil, Rússia, Índia e China, admitindo-se, posteriormente, a África do Sul. Para os fundadores, dois objetivos moviam o bloco: facilitar e fortalecer as relações entre os membros e coordenar posições diante das relações internacionais em esfera global. A primeira frente de ação tinha por fim a promoção de interesses nacionais dos setores econômicos envolvidos em transações com o exterior, porém a segunda destinava-se e influir sobre os parâmetros da ordem internacional. Constituído como bloco informal, o 


\section{Amado Luiz Cervo}

BRICS tem nas cúpulas convocadas regularmente sua instância decisória maior. Examinamos as duas últimas realizadas na China e na Índia.

A reunião de cúpula realizada em Sanya, na China, em abril de 2011, a terceira da série, incorporou a África do Sul como novo membro do grupo. Na agenda da reunião, três questões ocuparam os dirigentes: discutiram-se medidas para fomentar a utilização de moedas locais no comércio entre os países do grupo, outras medidas de controle dos preços de commodities agrícolas, enfim, a possibilidade de alcançar uma posição comum diante da intervenção da OTAN na Líbia. Ou seja, interesses próprios e segurança global.

A cúpula da China correspondeu a um fórum de debates de grandes questões acerca da ordem internacional atual. As reivindicações dos emergentes colocaram em alerta as potências que tradicionalmente exerciam o controle sobre o ordenamento global em seu benefício. Com efeito, a declaração final propôs a reforma da Organização das Nações Unidas e de seu Conselho de Segurança, especialmente em razão do aval que este Conselho deu ao uso da força pela OTAN na Líbia. A estratégia internacional de segurança conduzida pelos Estados Unidos desde a Segunda Guerra Mundial, com apoio da Europa e aval da ONU, estratégia movida pelo uso da violência da sanção ou da intervenção, é confrontada, pela primeira vez, de forma clara, por um agrupamento de países de peso sobre o cenário internacional. O BRICS propõe a substituição dessa estratégia da violência que submetia a si a segurança internacional pela estratégia pacífica da solução negociada de conflitos, sejam eles internos, regionais ou globais.

Outros dois aspectos da ordem internacional evidenciam a penetração dos emergentes no traçado de seus parâmetros a serem considerados pelas potências que sobre ela exerciam controle quase absoluto: a reivindicação de maior participação na direção dos órgãos econômicos multilaterais e de melhor regulamentação do sistema financeiro internacional, entregue nas últimas décadas ao excesso de liberdade, causa da especulação, dos desequilíbrios e da própria crise internacional oriunda do centro.

A quarta cúpula do BRICS realizada em Nova Deli, em fins de março de 2012, reforça os temas da anterior em direção à transformação da ordem internacional, porém as duas perspectivas de atuação do grupo se mantêm, considerando-se também a realização de interesses diretos de seus membros nas 
relações intra-bloco. Sob este último aspecto, discute-se a criação de um banco de desenvolvimento do grupo, medidas de fomento do comércio e do financiamento em moeda local, bem como de combate ao protecionismo. Em esfera global, insiste-se na formulação de posições mais claras e pontuais acerca dos desafios da segurança internacional consoante a estratégia de soluções negociadas, reivindica-se maior participação dos emergentes nas instituições da governança econômica e financeira.

Uma grande vitória já se alcançara no domínio da segurança global: Rússia e China haviam vetado no Conselho de Segurança o uso da força na crise da Síria, após o que sucedera na Líbia. Mas o BRICS se torna relevante para a gerência de toda ação internacional no Próximo Oriente, não só obstruindo a escalada da violência ocidental sob a égide da OTAN, especialmente no caso da Síria, mas ainda advertindo seus líderes no sentido de que desativassem a retórica da violência com relação ao programa nuclear iraniano.

Qual a importância do BRICS para a inserção internacional do Brasil? Duas observações podem contribuir para o entendimento da questão.

Uma linha de argumentação tende a diminuir a importância do BRICS para a inserção internacional do Brasil. Trata-se, segundo esse raciocínio, de um bloco com enorme heterogeneidade quanto à distribuição da renda, à capacitação militar, ao tamanho da riqueza nacional, à demanda nacional, ao grau de desenvolvimento, bem como ao grau de ambição de desempenhar papel relevante sobre o cenário internacional. A heterogeneidade, contudo, é característica de todos os blocos de nações resultantes de processos de integração nas últimas décadas. Poder-se-ia acrescentar, ademais, que os clubes de nações constituídos em fóruns decisórios fazem reuniões inócuas e de escasso efeito prático, sobretudo quando sua agenda é tal que envolve temas muito variados e superdimensionados, como é o caso das duas últimas cúpulas do BRICS. Se assim fosse, todavia, o velho G8, por exemplo, não teria influído sobre o traçado da ordem internacional, com fez efetivamente durante o longo tempo de sua atuação.

Outra linha de argumentação tende, contudo, a realçar o papel do BRICS para a inserção internacional do Brasil como nação capaz de influir sobre a transformação da ordem internacional e a promoção dos interesses dos países em desenvolvimento. A coordenação do grupo induz, com efeito, resultados positivos para satisfação de demandas individuais dos membros. Em 


\section{Amado Luiz Cervo}

2011, por exemplo, a China supera os Estados Unidos e alcança a condição de primeiro parceiro comercial do Brasil, enquanto o comércio intra-bloco cresce também e as relações econômicas são fortalecidas por meio de mecanismos variados de cooperação e de investimentos empresariais diretos. Por se tratar de grupo recente, sua irrupção sobre o cenário internacional se delineia com a aprendizagem natural dos processos de integração. A vontade de prosseguir e de construir o entendimento político é comum. Dois resultados já são perceptíveis: a mudança em curso da estratégia internacional de segurança e a redistribuição de poder em órgãos da governança financeira internacional. Em suma, o Brasil encontrou um assento entre grandes potências, envolve-se com a transformação da ordem no sentido de submetê-la gradualmente à correção de rumos, ou seja, à transição da assimetria para a igualdade entre as nações. Tudo sob os auspícios do tradicional interesse nacional, agora de país globalista, a defender e promover.

Ao lado da instrumentalização da integração e da formação de coalizões de poder, as parcerias do Brasil com outras nações ou com outras regiões constituem o terceiro fator, de mais acentuado caráter histórico, a reforçar, desde o exterior, a emergência do país sobre o cenário internacional.

Presumia-se que a globalização e o enfraquecimento do Estado conduzissem ao declínio do bilateralismo nas relações internacionais atuais. Esta não passou, no entanto, de uma expectativa frustrada de intérpretes da ordem internacional imbuídos de convicções neoliberais. $O$ bilateralismo apresenta-se como tendência que se fortalece no mundo atual. A Universidade de Brasília, dinâmico centro de estudos e de publicações acerca dos mais variados aspectos da inserção internacional do país, promoveu nos últimos anos a publicação de duas coleções de livros, com mais de duas dezenas de títulos lançados até 2012, voltados principalmente ao estudo das parcerias estratégicas, entendidas como a contribuição de um para a formação nacional do outro. Os estudos publicados pela Juruá Editora de Curitiba e pela Fino Traço Editora de Belo Horizonte focalizam as parcerias históricas e atuais consideradas relevantes para o desenvolvimento nacional e para a ascensão internacional.

Dentre os fatores de interpenetração de determinada parceria, destacase em primeiro lugar o econômico, especialmente o fluxo de capitais, empreendimentos e tecnologias, em razão de seus impactos sobre o bem estar da 
população. Outros fatores agem ao lado do econômico: a influência sobre a composição étnica, o perfil cultural, a filosofia política, bem como sobre a criação do quadro institucional e mesmo sobre padrões de conduta internacional. Como país novo, o Brasil tende a ser mais receptor que provedor de fatores da parceria. Historicamente, manteve a continuidade da estratégia de criação e consolidação de parcerias úteis à segurança e ao desenvolvimento econômico. Os dirigentes seguiram, desde o limiar do século $\mathrm{XX}$, o conselho do patrono de sua diplomacia, o Barão do Rio Branco: nação tranquila é nação que possa contar com inúmeros e bons parceiros, em primeiro lugar as potência hegemônicas, globais ou regionais.

Dentre as parcerias mais antigas, algumas feneceram com o tempo, como o nexo entre Brasil e Inglaterra no século XIX. A parceria entre Brasil e Estados Unidos veio substituí-la no século $\mathrm{XX}$, consolidando-se esse eixo de relações como o mais relevante para a formação nacional, jamais depreciado por governos ou regimes políticos até o presente. A ela se compara, em duração, apenas a parceria entre Brasil e Argentina.

Ao lado da parceria entre Brasil e Estados Unidos alinham-se por efeitos decrescentes sobre a formação nacional aquelas que vinculam há décadas o país ao exterior: Alemanha, Japão, Itália, Grã-Bretanha, Holanda, Suíça e Suécia, entre outras. Parcerias recentes emergem, entretanto, estabelecidas com Portugal e Espanha, por exemplo, mas nada afeta tanto a inserção internacional do Brasil como a recente parceria com a China, a qual, embora limitada, sobretudo, à dimensão comercial, reforça-se nos anos recentes com investimentos bilaterais e com entendimento político.

As regiões também alimentam a estratégia de confecção de parcerias por parte do Brasil. Assim encaminham-se parcerias entre Brasil e União Europeia, África e Ásia, esta última mais difusa.

O limite imposto à interdependência gestada no seio de parcerias é criado pela autonomia decisória. Um dilema, especialmente quando se trata de parcerias com potências hegemônicas. Sem autonomia decisória, entendeu-se no Brasil, não se realizam os benefícios esperados da parceria, desenvolvimento e segurança em primeiro lugar.

Conclui-se, pois, que as parcerias internacionais do Brasil contribuem tanto para sua formação nacional, isto é, seu desenvolvimento econômico, social e humano, quanto para a realização de interesses mediante a ação externa ou, 


\section{Amado Luiz Cervo}

ainda, para sua projeção internacional. Instrumentalização da integração, coalizões de poder e parcerias somam efeitos que se apresentam, enfim, como insumos externos que explicam a intensidade da emergência internacional do país.

\section{4 - Multilateralismo: o princípio da reciprocidade de benefícios}

Desde a criação do primeiro G20, o comercial, por ocasião da Conferência da OMC de Cancun em 2003, o multilateralismo da reciprocidade converte-se em conceito operacional da política exterior brasileira. A partir das negociações comerciais, as mais relevantes para as negociações multilaterais ao lado da segurança, são todas as dimensões da ordem internacional enquadradas no conceito de multilateralismo da reciprocidade: economia, comércio, segurança, questões ambientais, saúde e direitos humanos. A reciprocidade se estabelece quando as regras do ordenamento multilateral beneficiam a todas as nações. Consequentemente, quando afastam uma ordem que beneficia nações mais avançadas, assegurando ou prolongando assimetrias.

Os pressupostos do multilateralismo da reciprocidade são dois: a necessidade de regras para o ordenamento internacional sem as quais irá prevalecer a disparidade de poder em benefício das grandes potências; e a elaboração conjunta dessas regras de modo a garantir reciprocidade de efeitos para que não realizem interesses de uns em detrimento de outros.

O multilateralismo da reciprocidade elimina duas utopias teóricas para compreender a política exterior do Brasil: a da estabilidade hegemônica e a do vínculo necessário entre política exterior e regime político. Tão decantada pela teoria das relações internacionais formulada em sociedades anglo-saxônicas, a estabilidade hegemônica tanto fundamento exibe, segundo Bertrand Badie, quanto a instabilidade hegemônica. A crise financeira e econômica desde 2007 convence o leitor disso. O nexo entre regime político e política exterior é tal que, consoante o ensinamento da história das relações internacionais, independentemente da natureza do regime, um Estado pode contribuir para a reciprocidade ou para a assimetria internacional.

Movida pelo conceito operacional do multilateralismo da reciprocidade, a política exterior brasileira se desdobra em cinco linhas de ação: a) para as regras da economia internacional, postula o fim do velho G8 e sua substituição 
pelo G20 financeiro, o primeiro fórum decisório multilateral que reúne países avançados e emergentes; b) na esfera do comércio internacional, diante da sutil distorção promovida pelos países avançados substituindo o acordo global a ser negociado no seio da OMC pelo Tratado de Livre Comércio, que perpetua a velha ordem, a diplomacia brasileira malogra; c) no domínio da segurança internacional, a substituição da estratégia da violência mantida pela OTAN pela estratégia da solução negociada de conflitos concebida no seio do BRICS; d) quanto ao meio ambiente, a posição brasileira evolui de vítima à corresponsabilidade; e) enfim, no que tange o respeito aos direitos humanos, a ação diplomática brasileira desmascara a práxis do choque de civilizações ou ideologias e requer o respeito universal por parte de todos os governos.

Foram alcançados por certo resultados pela negociação multilateral movida à base do multilateralismo da reciprocidade nessas frentes da ação, resultados que modificam a ordem internacional. Um bom exercício de investigação consistiria em mensurá-los. O mais minguado efeito, contudo, parece situar-se no domínio do comércio internacional, cujas regras mantêm-se obsoletas e ineficientes. Para o Brasil, um desafio que convém ao novo governo de Dilma Rousseff enfrentar: diante do malogro, qual a melhor política de comércio exterior para o país, prosseguir na busca do acordo global consoante a reciprocidade, acordo inatingível ao que parece, ou domar a natureza do acordo bilateral de livre comércio? A tentação da segunda opção se põe, por certo, especialmente quando a secretária de Estado, Hilary Clinton, em visita a Brasília no mês de abril de 2012, propõe à presidente Rousseff o acordo bilateral de comércio entre Brasil e Estados Unidos.

\section{5 - As três estratégias de poder traçadas pelo BRICS}

A transformação da ordem internacional, cujos ordenamentos eram traçados pelas nações avançadas da Segunda Guerra Mundial ao início do século XXI, constitui o objetivo essencial do BRICS, a razão de sua existência como coalizão de poder. Essa transformação desejada anima as cúpulas do grupo e são perceptíveis em três esferas. Convém organizar e condensar, pois, a análise acima exposta a respeito da atuação do BRICS e da posição do Brasil no seio da coalizão.

Assim como o grupo supõe representar os interesses dos países em desenvolvimento em seu intento de promover a inclusão social internamente, na 


\section{Amado Luiz Cervo}

esfera internacional a ordem deve ser posta a serviço da promoção da igualdade entre as nações. Não se trata de ideologia, retórica ou utopia, mas de mecanismos concretos que afastem a figura daqueles que chutaram a escada após alcançar o topo do bem estar interno e internacional no sistema de economia de mercado.

A segurança internacional também requer uma mudança estratégica em seu gerenciamento para transitar de mecanismos de uso da força, como sanção e intervenção, para soluções negociada de conflitos. Todas as nações, por exemplo, tem direito de acesso à tecnologia nuclear para uso econômico e pacífico, não se admitindo que seja este privilégio consolidado de uns poucos. A negociação, mais uma vez, deve ser posta nesse domínio como garantia da segurança. Intervenções fundadas no privilégio, como a que possivelmente adviria das ameaças ocidentais ao Irã, infringem a visão da segurança internacional do BRICS.

Como o G20 financeiro constitui outro fórum informal, o BRCS reivindica para os países emergentes maior representatividade nos órgãos multilaterais que exercem o poder decisório efetivo sobre as finanças internacionais, como Banco Mundial e FMI. Usa suas enormes reservas monetárias, os fundos soberanos, que são repassados ou não, na medida da obtenção de maior representação e poder decisório junto aos referidos órgãos, por meio de reforma do sistema de quota e de votos e eliminação de tradicionais orientações que venham limitar a autonomia das políticas nacionais nas áreas fiscal e financeira. Inclusão internacional e segurança internacional dependem, na visão do BRICS, do poder econômico, por isso as três estratégias de ação são programadas simultaneamente.

\section{6 - Internacionalização: a maturidade sistêmica da economia brasileira}

No século XXI encaminha-se a mais relevante condição para a ascensão do Brasil como país globalista, isto é, dá-se o passo definitivo rumo à maturidade sistêmica. A internacionalização da economia brasileira somente torna-se viável, entretanto, com o aporte da sociedade mais que do Estado, o qual, por sua vez, se adapta e assume a funcionalidade de Estado Logístico. Vinculamos, destarte, os elementos de nosso raciocínio: Estado Logístico, 
emergência da sociedade, instrumentalização e reforço do poder nacional, maturidade sistêmica.

A expansão para fora das empresas brasileiras transforma-se em objetivo do Estado e da sociedade. Consiste em formar empresas fortes com capacidade de se estabelecer e competir em escala global. As condições para deslanchar o processo de internacionalização foram estimuladas pelos presidentes Cardoso, que privatizou nos anos 1990, e Lula, que conglomerou a seguir. As duas fases, fortalecimento empresarial interno e expansão externa, contaram com o envolvimento entusiasta do empresariado e o apoio de fortes instituições financeiras do Estado, como o BNDES e o Banco do Brasil.

Após um início tímido nos anos anteriores, a internacionalização da economia brasileira acelera o ritmo a partir de 2005. Os investimentos diretos brasileiros no exterior apresentam desde então um crescimento médio de $14 \%$ ao ano. Em alguns anos, superam os investimentos estrangeiros no Brasil. 0 movimento dos empreendimentos brasileiros acompanha os emergentes: estes detêm cerca de 5\% dos investimentos diretos no exterior em 1990 e mais de $20 \%$ em 2007. Neste ano, com 108 bilhões de dólares consolidados, o Brasil tornou-se o segundo investidor externo entre os emergentes e no ano seguinte, 2008, esse montante atinge 149 bilhões de dólares, ano em que os investimentos estrangeiros no Brasil somaram 34,6 bilhões, um crescimento de $100 \%$ relativamente ao ano anterior. A tendência de alta também se observa no montante das reservas internacionais do Brasil, que aumentam de 200 bilhões de dólares em fim de 2008 para 370 bilhões em abril de 2012. Após haver o país recebido o grau de investimento por agências de classificação de risco, reservas e fluxos externos de investimentos mantém tendência firme de alta até o presente, o que também encontra explicação na expectativa de rentabilidade das inversões dos países ricos em países emergentes durante a crise econômica que assola o antigo primeiro mundo.

A destinação geográfica dos investimentos diretos brasileiros no exterior se desloca em 2006, grosso modo, da vizinhança para o mundo: Estados Unidos, Canadá, África e Europa. Grandes grupos, como Vale do Rio Doce e Petrobras puxam a tendência, seguidos por Gerdau, Embraer, Odebrecht, Itaú, Braskem, Votorantim, Camargo Correia, AmBev e WEG entre outros. A especialização dos grupos indica que as empresas brasileiras atuam no exterior em diferentes áreas, como mineração, prospecção, metalurgia, indústria e tecnologia. O marco 


\section{Amado Luiz Cervo}

cronológico de 2006 se explica em razão de entraves na Bolívia e depois em outros países vizinhos, que cerceiam expectativas de investidores. Trata-se de dificuldades criadas por ordenamentos jurídicos e atitudes políticas na vizinhança. Entre 2001 e 2008, a Argentina passa de 15\% a 9\%, entre 2001 e 2010 , os Estados Unidos, que se tornam o principal destino, passam de $13 \%$ a $37 \%$ sobre o total de IDEs brasileiros no exterior. Ademais, em fins de 2011, o Brasil tornou-se o sexto maior investidor externo na Europa, com 80 bilhões de dólares, embora a superioridade dos investimentos europeus no Brasil, 180 bilhões de dólares, ainda se mantenha. Nesse ano, os investimentos brasileiros na Europa e europeus no Brasil elevam-se acima da soma de idênticos fluxos atinentes a China, Rússia e Índia, indicando o elevado grau comparativo de internacionalização da economia brasileira entre as economias emergentes.

Analistas da Fundação Getúlio Vargas observam outra reorientação geográfica da internacionalização da economia brasileira por volta de 2010: o nexo chinês. Impulsionado pelo comércio nos anos anteriores, este nexo incorpora, enfim, os esperados fluxos de investimentos chineses no Brasil.

Em realidade, Brasil e China descolam-se dos Estados Unidos rumo à autonomia de movimento tanto em âmbito bilateral quanto global. $O$ novo ciclo de comércio e investimentos bilaterais toma impulso em 2010 e se orienta por interesses próprios. O Conselho Empresarial Brasil-China observa, em 2011, uma mudança de qualidade e quantidade em curso no intercâmbio econômico bilateral. A balança do comércio passa de 9 bilhões de dólares em 2004 para 56 bilhões, sete anos depois. Expande-se 52\% em 2009-2010, quando a China se torna o principal parceiro comercial do Brasil. Em 2010, os investimentos chineses irromperam. Ou seja, o relacionamento econômico bilateral entra em nova fase e evidencia ritmo acelerado.

As motivações dos empresários que investem no exterior são variadas: a moeda valorizada aconselha adquirir ações de multinacionais; a abertura de filiais, a associação ou a compra de outras empresas favorecem a captação de recursos financeiros no exterior; desenvolvimento tecnológico e elevação da produtividade ao nível sistêmico global são efeitos também esperados; enfim, com operações no exterior, as empresas pretendem estimular exportações de maior qualidade. A melhor de todas as motivações, entretanto, consiste na 
elevação da produtividade empresarial que a penetração nas cadeias produtivas de redes globais faculta.

Dois exemplos, escolhidos aleatoriamente, ilustram esses resultados positivos da globalização da economia brasileira: a Embraer e a WEG. Privatizada em 1994, com lastro de conhecimento tecnológico acumulado por dois centros anteriores, o Centro Brasileiro de Aeronáutica e o Instituto Tecnológico da Aeronáutica, a Empresa Brasileira de Aeronáutica (Embraer) voltou-se para o mercado global, agregou novos processos de inovação, estabeleceu a interdependência empresarial com suas parcerias, proveu seu caixa e especializou-se para competir. Anos depois, tornou-se o terceiro fabricante de jatos regionais no mundo e seus produtos chegaram a ocupar o primeiro lugar na pauta da exportação brasileira. Em 2012 venceu licitação para fornecer à Força Aérea dos Estados Unidos aviões de combate Super Tucano, um verdadeiro selo de qualidade para avançar sobre outros mercados, caso o negócio se conclua.

Empresa industrial especializada na fabricação de motores e outros equipamentos elétricos, a WEG, originária de Jaraguá do Sul em Santa Catarina, está presente em uma centena de países para assistência técnica e em países chaves com suas fábricas: no México, visando o mercado do Nafta, e em Portugal, visando o da União Europeia.

\section{7 - Limitações do Estado Logístico}

A nova funcionalidade do Estado Logístico fica por certo evidente ao impulsionar a economia nacional a patamar de interdependência global que a movimenta rumo à maturidade. $\mathrm{O}$ Estado Logístico brasileiro não alcança, entretanto, a plenitude de efeitos que dele se presume esperar.

Três fatores limitam a eficiência do Estado Logístico no Brasil. Em primeiro lugar, a baixa inovação. Esta decorre de ensino deficiente, da insuficiência de centros de pesquisa tecnológica como aqueles que explicam a criação da Embraer e da insuficiência de preparo técnico para a mão de obra. Como entender, nessas circunstâncias, o atual programa de milhares de bolsas a serem concedidas a estudantes de graduação no exterior e a carência de investimentos em centros de pesquisa, cujos embriões se localizam nas Universidades ou institutos do país? Em segundo lugar, a baixa competitividade dos sistemas produtivo e de serviço, devida à baixa inovação, por certo, mas também a infraestrutura ineficaz, energia cara, burocracia 
discricionária, carga tributária, juros bancários e câmbio elevados. $O$ terceiro fator de peso a limitar a eficiência do Estado logístico no Brasil consiste no funcionamento do governo de coalizão. Este modelo político que submete a distribuição dos cargos públicos ao apoio do partido ao governo de coalizão compromete a natureza do Estado por modo a deslocar a governabilidade, da eficiência ao proveito partidário ou pessoal, e a abrir o canal da corrupção.

O pesado fardo de ineficiência do Estado reduz a competitividade sistêmica. Associada a certo grau de aversão do empresariado ao risco da competitividade, a ineficiência explica, além das limitações do Estado Logístico acima descritas, a queda da indústria, de $30 \%$ do PIB no século XX para $15 \%$ em 2011, segundo cálculos do Instituto Brasileiro de Geografia e Estatística.

As funções e as limitações do Estado Logístico o situam em contraposição ao Estado neodesenvolvimentista, cujo conceito alguns economistas, a exemplo de Bresser Pereira, supõem equivocadamente orientar as estratégias brasileiras no século XXI.

São componentes do Estado Logístico: multilateralismo da reciprocidade, internacionalização econômica, abertura do mercado de consumo bem como dos sistemas produtivo e de serviço, estabilidade monetária e moeda forte, agências de fomento, equilíbrio financeiro interno e externo, ascensão da sociedade e diminuição do Estado, organização social avançada, competitividade sistêmica global elevada. Em síntese, inserção interdependente no capitalismo maduro, sendo o Brasil o protótipo desse modelo na América do Sul.

São componentes do neodesenvolvimentismo: reestatização, protecionismo do mercado de consumo, instabilidade monetária e moeda fraca, desequilíbrio financeiro externo, introspecção econômica sem internacionalização, assimetria ou dependência estrutural relativamente às nações desenvolvidas, oscilações das estratégias interna e externa, sendo a Argentina protótipo do modelo.

Em comum, ambos os paradigmas de Estado executam programas de inclusão social e alcançam resultados nesse terreno, o que eventualmente confunde alguns economistas no uso dos conceitos.

Conclusão 
As relações internacionais do Brasil no século XXI são orientadas por dois objetivos gerais: a realização de interesses nacionais e a contribuição para a reforma da ordem internacional.

Os pressupostos que suportam a ação externa compreendem, em primeiro lugar, ideias e valores. $O$ meio dirigente revela a convicção de que convém ao país desempenhar papel relevante sobre o cenário internacional e tal convicção resulta em desígnio nacional, ao ser assimilada pelas lideranças sociais. As ideias que geram tal desígnio fundamentam-se em base cultural interna. $\mathrm{O}$ multilateralismo da reciprocidade, segundo o qual os benefícios da ordem internacional devam espalhar-se sobre todas as nações, promover a igualdade e atenuar assimetrias entre elas. As negociações diplomáticas multilaterais destinam-se, segundo esse conceito, a produzir regras relativas ao comércio, às finanças e às questões ambientais benéficas para todos, especialmente para as nações vítimas da globalização assimétrica. 0 universalismo da política internacional afeta, por outro lado, os direitos humanos: a serem respeitados por todos, grandes, pequenas e médias potências, e jamais posto a serviço de ideologias e culturas específicas, como tem ocorrido. A convivência de diferenças, em outras palavras, induz o desmonte do choque de civilizações e da estabilidade hegemônica, teorias e práticas postas a serviço de grandes potências.

Os meios de ação agregados às relações internacionais do país nas duas últimas décadas foram, simultaneamente, a nova funcionalidade do Estado, que denominamos de Estado Logístico, e a emergência da sociedade, a cujos atores não estatais esse novo Estado repassa poder e responsabilidade acerca dos objetivos externos e da realização do interesse nacional.

Como sem poder nada se alcança em relações internacionais, ao lado da invenção de novo nexo entre Estado e sociedade, cuidou-se de reforçar o poder nacional por meio de insumos também externos. A integração regional, no século XXI, adquire caráter instrumental nesse sentido, deixando de ser um fim em si e modificando-se de prioridade alta para prioridade baixa, sem sacrificar o conveniente entendimento político com a vizinhança. As coalizões emergentes, Unasul, BRICS e Ibas, dentre as mais relevantes, são responsáveis por importante aporte de poder. Não menos importante, contudo, são as parcerias tradicionais, como Estados Unidos, Alemanha, Argentina, Itália, Japão, França, Grã-Bretanha, e as novas, como Portugal, Espanha e China, entre 


\section{Amado Luiz Cervo}

outras. As parcerias estendem a rede de relações internacionais do país por sobre o planeta inteiro e reforçam sua capacidade de ampliar vínculos benéficos.

$O$ resultado mais relevante para o interesse nacional dessa estratégia conjugada entre Estado Logístico e sociedade toma forma na internacionalização da economia brasileira. Respondendo positivamente ao desafio da globalização, o país alcançou no século XXI o grau de maturidade de interpendência econômica própria de nações avançadas, indo atrás dos benefícios de operar em condições de produtividade sistêmica global.

Limites de eficiência permanecem, contudo, a condicionar Estado e atores não governamentais e encurtar resultados. Um empresariado afeto à inovação tecnológica em grau insuficiente e um Estado repleto de percalços gerenciais. Somando a ineficiência de ambos, o país se depara com baixa competitividade relativa em razão de precária infraestrutura, da escassez de investimentos em centros tecnológicos, do juro e do câmbio valorizados, de carga tributária exorbitante, entre outros fatores. Carece, ademais de estratégia industrial adaptada à nova situação e mesmo de política de comércio exterior, após o malogro do multilateralismo nesse domínio. Longo percurso tem pela frente.

\section{REFERÊNCIAS}

ALMEIDA, Paulo Roberto de. Relações internacionais e política externa do Brasil. Rio de Janeiro: LTC, 2012.

BADIE, Bertrand. L'Impuissane de la puissance: essai sur les nouvelles relations internationales. Paris: Fayard, 2004.

BARROS, Octavio de \& Giambiagi, Fábio (orgs.). Brasil globalizado: o Brasil em um mundo surpreendente. Rio de Janeiro: Elsevier, 2008.

BERNAL-MEZZA, Raúl. América Latina en el mundo: el pensamiento latinoamericano y la teoría de relaciones internacionales. Buenos Aires: Nuevohacer, 2005.

BRASIL, Ministério das Relações Exteriores. Política Externa Brasileira, II. Brasília: Funag, 2007. Idem, Resenha de Política Exterior do Brasil, n. 96 e 97, 2005.

BRASIL, Ministério das Relações Exteriores O G-20 e a OMC: textos, comunicados e documentos. Brasília: Funag, 2007.

BRESSER PEREIRA, L. C. From old to new developmentalism in Latin America. In: Ocampo, J. A. \& Ross, J. (Eds.). Handbook os Latin America Economics. Oxford: Oxford University Press, 2011, p. 108-129. 
CERVO, Amado Luiz. Inserção internacional: formação dos conceitos brasileiros. São Paulo: Saraiva, 2008.

CERVO, Amado Luiz e Bueno, Clodoaldo. História da política exterior do Brasil. Brasília: EdUnB, 2011 (4ª Edição).

CERVO, Amado Luiz. Relações internacionais da América Latina: velhos e novos paradigmas. São Paulo: Saraiva, 2007.

DUPAS, Gilberto. Atores e poderes na nova ordem global: assimetrias, instabilidades e imperativos de legitimação. São Paulo: UNRSP, 2005.

FLEMES, Daniel. O Brasil na iniciativa BRIC: soft balancing numa ordem global em mudança? Revista Brasileira de Política Internacional, n. 53 (1), p. 141-156, 2010.

GARCIA, Eugênio Vargas (org.). Diplomacia brasileira e política exterior: documentos históricos (1492-2008). Rio de Janeiro: Contraponto, 2008.

LIMA, Maria Regina Soares de \& Hirst, Monica (orgs.). Brasil, Índia e África do Sul: desafios e oportunidades para novas parcerias. São Paulo: Paz e Terra, 2009

MARTINEZ, Maria Regina Estevez. A globalização da indústria aeronáutica - o caso da Embraer. Brasília: Universidade de Brasília, Tese de doutorado, 2007.

RAPOPORT, Mario. Historia Económica, Política y Social de la Argentina. Buenos Aires: Ariel, 2006.

ROLLAND, Denis \& Lessa, Antônio Carlos (Eds.). Relations internationales du Brésil: les chemins de la puissance. Paris: L'Harmattan , 2010, 2 vol.

SILVA, André Luiz Reis da. Do otimismo liberal à globalização assimétrica. Curitiba: Juruá, 2009.

SANTOS, Sergio Caballero. Brasil y la región: una potencia emergente y la integración regional sudamericana. Revista Brasileira de Política Internacional, 54 (2), p. 158-172, 2011.

VISENTINI, Paulo Fagundes. As relações diplomáticas da Ásia. Belo Horizonte: Fino Traço, 2011.

Os principais sites utilizados pertencem às seguintes instituições e fornecem dados estatísticos bem como análises conjunturais: Ministério das Relações Exteriores; Universidade de Brasília (Mundorama, Cena Internacional, Meridiano 47); Universidade de São Paulo (Carta Internacional, Contato); Instituto de Pesquisa do Rio de Janeiro (Observatório Político Sul-Americano); Conselho Empresarial Brasil-China; Grupo de Estudos de Defesa e Segurança Internacional (GEDES); Instituto Brasileiro de Geografia e Estatísticas (IBGE); Banco Central do Brasil; Pontifícia Universidade Católica do Rio de Janeiro (BRICS Policy Center); Fundação Getúlio Vargas (The Brazilian Economy); Juruá Editora; Fino Traço Editora. Foram consultados igualmente os jornais Valor Econômico e O Estado de S. Paulo. 


\section{Amado Luiz Cervo}

\section{RESUMO}

A inserção internacional do Brasil é conduzida no século XXI pela nova funcionalidade do Estado, que denominamos de Estado Logístico, em estreita cooperação com atores não governamentais que se fortalecem desde os anos $1990 \mathrm{em}$ razão da emergência da sociedade. Conceitos, valores e desígnios constituem pressupostos internos que se associam ao reforço de poder advindo da integração, de coalizões emergentes e de parcerias bilaterais. $O$ resultado mais relevante rumo à maturidade da inserção internacional advém da internacionalização da economia brasileira. Verificam-se, porém, entraves no Estado e na sociedade que estabelecem limites de eficiência à ação externa.

\section{PALAVRAS-CHAVE}

Estado Logístico; Ordem Mundial; Multilateralismo; 